\title{
MRKH syndrome and Turner syndrome co-existing in a patient with primary amenorrhoea
}

\author{
Mohammad Moin Shahid \\ Department of Endocrinology, Ad-din women's medical college, Dhaka, Bangladesh \\ Abstract \\ Mayer-Rokitansky-Haüser-Kuster (MRHK) or Mullerian agenesis syndrome is characterized by aplasia or hypoplasia of uterus \\ and upper $2 / 3$ of the vagina. Patients usually have normal gonadal function as both ovaries develop from different embryonic \\ sources. Due to functioning gonads, despite being present with primary amenorrhoea, patients develop secondary sexual \\ characteristics. \\ Turner syndrome is a disorder characterized by the absence of all or part of a normal second sex chromosome, sometimes \\ with mosaicism of $45 \mathrm{X}$ with another cell line. Patients are phenotypically female present with short stature, often absent \\ secondary sexual characteristics due to gonadal dysgenesis. \\ Co-existence of both syndromes is very rare. We describe here a 16-year old girl present with primary amenorrhoea, absenting \\ secondary sexual characteristics and short stature.
}

Keywords: Müllerian agenesis, Gonadal dysgenesis, Primary amenorrhoea, Secondary sexual characteristics.

Correspondence email: dr.ms952@gmail.com

ORCID ID: https:// orcid.org/0000-0003-4797-2686

Copyright: This is an open-access article distributed under the terms of the Creative Commons Attribution License, which permits unrestricted use, distribution, and reproduction in any medium, provided the original author and source are credited (CC BY 4.0)

\section{Introduction:}

Primary amenorrhea is defined either as absence of menarche by 14 years of age in the absence of secondary sexual characteristics or absence of menses by 16 years in the presence of normal growth and secondary sexual characteristics ${ }^{(1)}$. MRKH syndrome and Turner syndrome are the 2 most common causes of primary amenorrhoea (2), although MRKH syndrome and Turner syndrome have the incidence of 1:4500-5000 and 1:2500 in female live births respectively(3)(4)(5). Few cases have been reported so far regarding the co-existence of both syndromes ${ }^{(3)}$.

\section{Case presentation:}

A 16-year old girl came with the complaints of absence of menarche and stunted growth. She was a full term normal vaginal delivery born out of a non-consanguineous marriage. She had normal milestones with no history of any chronic illness or genetic disease. She had normal mentation with good school performance. During patient's birth, her mother was 26 and had an insignificant gestational period. The patient had been fully vaccinated. Her siblings were healthier and taller than the patient.
On examination, she weighed $22 \mathrm{~kg}$ and her height was 123 $\mathrm{cm}$ which was below 5 th percentile of her age. Her mid parental height was $154 \mathrm{~cm}$. Her breast and pubic hair development were at Tanner's stage 1. Her genitalia appeared normal externally. There were presence of low set of ears, epicanthal fold, micrognathism, fish-like mouth and shield chest with wide nipples (figure - 1,2). However low hairline, webbing of neck, high arched palate, increased carrying angle, skeletal deformities were absent. Her cardiovascular, pulmonary, abdominal system examinations revealed no abnormality.

Complete blood counts, routine microscopic examination of urine and serum creatinine were normal. Echocardiogram was normal as well.

Her fasting levels of thyroid stimulating hormone(TSH), follicular stimulating hormone (FSH), luteinizing hormone $(\mathrm{LH})$ were $3.19 \mu \mathrm{IU} / \mathrm{mL}(.7-5.7 \mu \mathrm{IU} / \mathrm{mL}), 19.5$ $\mathrm{IU} / \mathrm{L}(0-4 \mathrm{IU} / \mathrm{L}), 30.4 \mathrm{IU} / \mathrm{L}(.02-5 \mathrm{IU} / \mathrm{L})$ respectively. Xray of left hand suggested patient's bone age was around 10-11 years. Ultrasonogram (USG) and Magnetic Resonance Imaging (MRI) with contrast of whole abdomen confirmed the absence of adnexa, uterus and upper part of the vagina with horseshoe kidneys as well as right sided 
gross hydronephrosis(figure - 3, 4). Karyotyping was found in favour of Turner syndrome - 45, X0.

It was decided to initiate combination of estrogen and growth hormone therapy for sexual development and bone growth with a plan to add progesterone hormone therapy later on. Patient and her parents were counseled about the treatment plan and the fate of this condition. Surgical reconstruction of genitalia can be done in future to improve her sexual life, but the chances of induction of menstruation and conception are extremely unlikely.

\section{Discussion:}

Müllerian agenesis is caused by the developmental defect of mullerian duct during embryonic stage resulting aplasia or hypoplasia of uterus and upper $2 / 3$ of the vagina. The exact pathogenesis of mullerian agenesis is still not clear. Scientists recently have identified association of MRKH with multiple genes, such as ESR1, OXTR, HNF1B, LHX1, HOXA7, HOXA9-13, HOXD9-13, WNT4 but any definitive conclusion regarding genetic involvement is yet to be decided (4)(6). Although some investigators consider this entity to be inherited in autosomal-dominant or multifactorial mode, others believe that it is sporadic in origin (6). MRKH syndrome has been subdivided into 2 types: type A, presents with isolated mullerian duct malformations such as a shallow vaginal dimple with absent cervix, uterus, and upper vagina and is not associated with other anomalies; type B, presents with the features of type A as well as varying degrees of congenital malformations, like - renal agenesis, horseshoe kidney, scoliosis, spina bifida, auditory defects, alimentary tract malformations, cardiac anomalies ${ }^{(5)(7)}$. sometimes with mosaicism of $45 \mathrm{X}$ with another cell line. Premature loss of ovarian function is very common. Most of the ovarian tissues degenerates before birth, so rarely an affected girl can go through puberty without hormone therapy (8). Sexual infantilism at puberty secondary to gonadal dysgenesis and short stature are the cardinal features of turner syndrome. Early childhood presentations are lymphedema of the extremities and loose skin folds over the nape of the neck. In later life, low hairline on the back of neck, short-webbed neck, shield like chest, wide set of nipples, micrognathia, epicanthal folds, prominent low-set ears, a fish-like mouth, high arched palate and ptosis maybe present to varying degrees. Turner syndrome is commonly associated with skeletal, renal \& cardiac anomalies, e.g. short fourth metacarpals and metatarsals, madelung deformity, scoliosis, horseshoe kidney, hydronephrosis, valvular defects, etc.(9)(10). There is high prevalence of otitis media which often leads to hearing loss (9)(10). Usually Turner syndrome isn't inherited except some rare conditions where causative partially deleted " $\mathrm{X}$ " chromosome can be transferred from one of the parents ${ }^{(8)}$. Genetic linkage between these 2 syndromes are yet to be determined.

\section{Conclusion:}

Co-existence of MRKH \& Turner syndrome is rare; therefore management is somewhat complicated. Early diagnosis and regular follow up can improve the condition of patient's life. But it is very important for the family \& friends to understand the management and fate of this condition so that they can help the patient to overcome various psychological and social barriers.

Turner syndrome is a disorder characterized by the absence of all or part of a normal second sex chromosome,

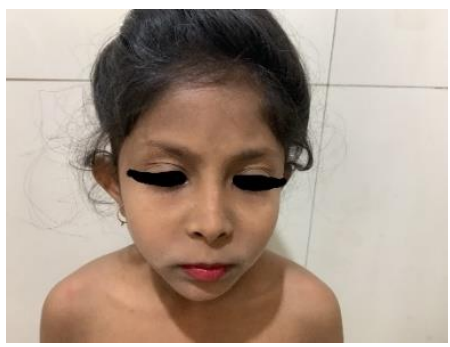

Figure 1 is showing the presence of epicanthal fold, low set of ears, fish-like mouth and micrognathism.

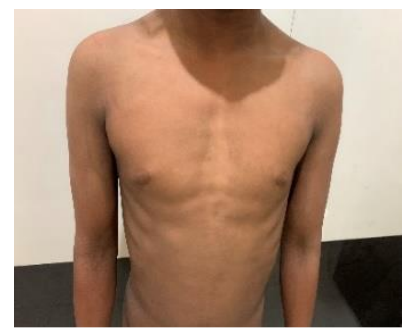

Figure -2 is showing the shield chest with wide nipples and absence of breast development 


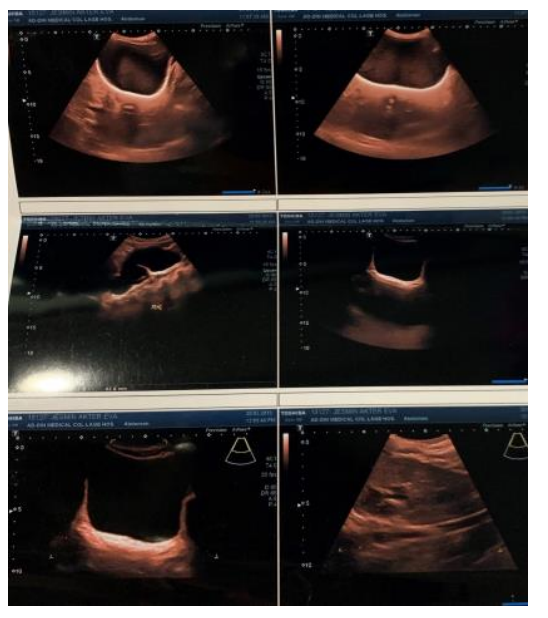

Figure -3 , ultra sonogram of abdomen is showing dilated right kidney as well as absent uterus and adnexa.

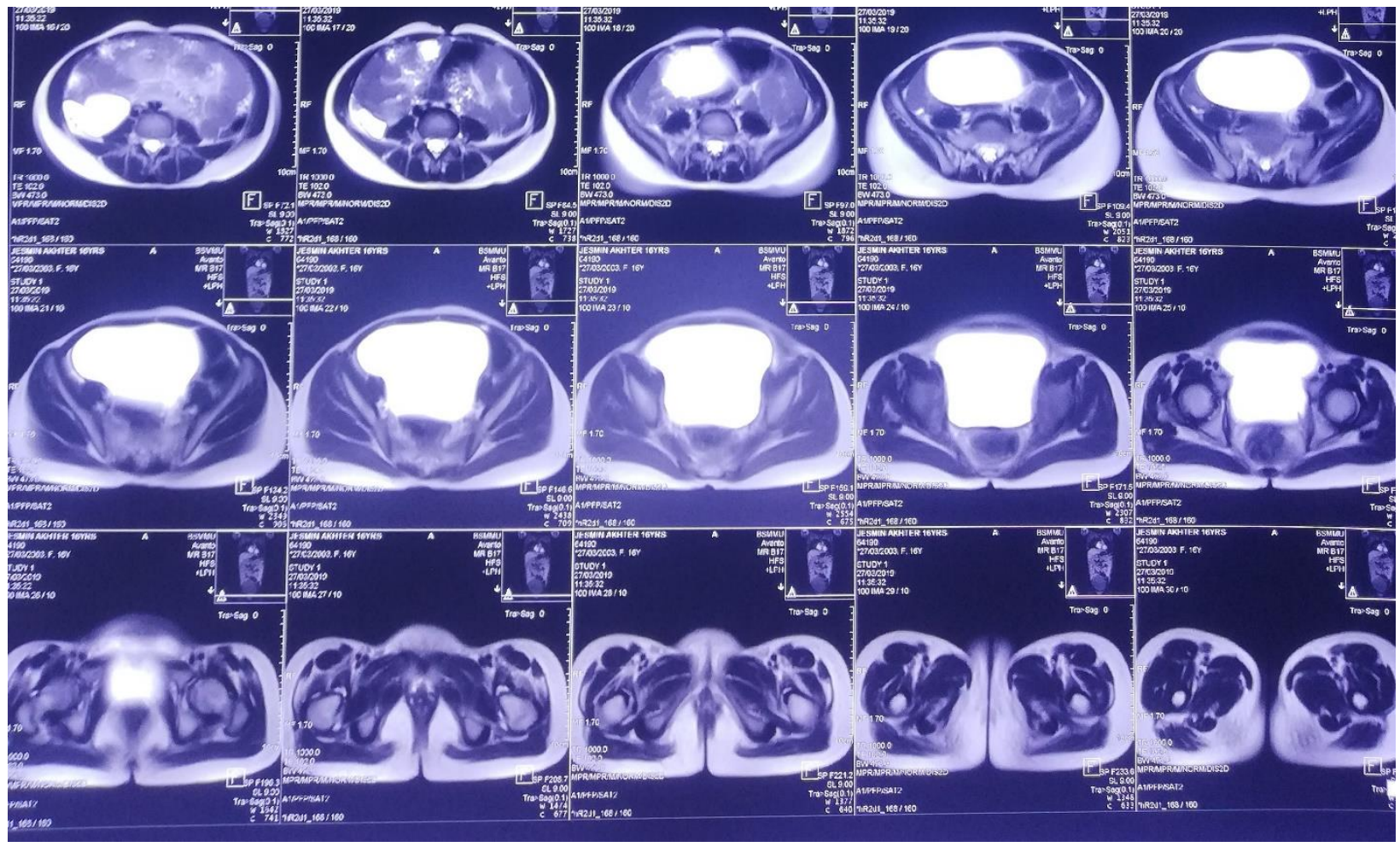

Figure -4 , MRI of abdomen is showing the absence of adnexa, uterus and upper part of the vagina with horseshoe kidney as well as right sided gross hydronephrosis. 
References:

1. Doody KM, Carr BR. Amenorrhea. Obstetrics and gynecology clinics of North America. 1990;17(2):361-87.

2. Kriplani A, Goyal M, Kachhawa G, Mahey R, Kulshrestha V. Etiology and management of primary amenorrhoea: A study of 102 cases at tertiary centre. Taiwan J Obstet Gynecol [Internet]. 2017;56(6):761-4. Available from: https://doi.org/10.1016/j.tjog.2017.10.010

3. Meena A, Daga MK, Dixit R. Unusual association of turner syndrome and mayer-rokitansky-küster-hauser syndrome. BMJ Case Rep. 2016;2016:1-5.

4. Miao Y, Wen J, Huang L, Wu J, Zhao Z. Diagnosis and Management of Ovarian Tumor in Mayer-Rokitansky-KüsterHauser (MRKH) Syndrome. Biomed Res Int. 2018;2018:1-6.

5. ACOG Committee Opinion No. 728 Summary: Müllerian Agenesis: Diagnosis, Management, And Treatment. Obstet Gynecol. 2018;131(1):196-7.

6. Narang K, Cope ZS, Teixeira JM. Chapter 6 - Developmental Genetics of the Female Reproductive Tract. In: Leung PCK, Qiao J, editors. Human Reproductive and Prenatal Genetics [Internet]. Academic Press; 2019. p. 129-53. Available from: http://www.sciencedirect.com/science/article/pii/B9780128135709000061

7. II DSB, Mousa SA. Mayer-Rokitansky-Kuster-Hauser syndrome: complications, diagnosis and possible treatment options: a review. Gynecol Endocrinol [Internet]. 2014;30(9):618-23. Available from: https://doi.org/10.3109/09513590.2014.927855

8. Conditions G. Genetics Home Reference : Turner syndrome.

9. Gardner DG SD. Greenspan's Basic and Clinical Endocrinology. Ninth Edition. 2004. p. 495-6.

10. Bondy CA. Clinical practice guideline: Care of girls and women with Turner syndrome: A guideline of the Turner Syndrome Study Group. J Clin Endocrinol Metab. 2007;92(1):10-25. 